\title{
Artesunate-Induced Severe Autoimmune Hemolytic Anemia in Complicated Malaria
}

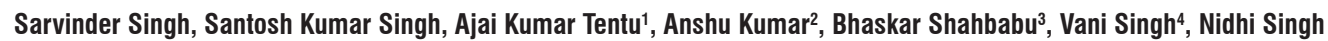 \\ Departments of Medicine, ${ }^{1}$ Pulmonary Medicine, ${ }^{2}$ Microbiology and ${ }^{3}$ Preventive and Social Medicine, Military Hospital, ${ }^{4}$ Department of Radiation Oncology, \\ RIMS, Ranchi, Jharkhand, India
}

\section{Abstract}

Autoimmune hemolytic anemia (AIHA) is a very rare cause of anemia in a case of malaria and drug-induced AIHA is even rarer. A 50-year old patient with a history of fever for 8 days was diagnosed with a case of complicated malaria with mixed infection having initial parasite index of $45 \%$. He showed good response on initial therapy with artesunate (parasite count reduced to $<1 \%$ ) but his haemoglobin (Hb) continued to drop from $12 \mathrm{~g} \%$ to $4.9 \mathrm{~g} \%$ over a course of 11 days. Direct coombs test was positive with reduced haptoglobin and increased lactate dehydrogenase suggesting AIHA. The patient was put on steroids and transfused with saline washed O-negative blood. He gradually recovered over 8 weeks with $\mathrm{Hb}$ level rising up to $12 \mathrm{~g} \%$. This is a rare case of AIHA following treatment of severe malaria with parenteral artesunate suggesting of the drug immune-related mechanism.

Keywords: Anemia, artesunate, autoimmune hemolytic anemia, hemolytic, malaria

\section{INTRODUCTION}

Autoimmune hemolytic anemia (AIHA) is a very rare cause of anemia in a case of malaria. ${ }^{[1]}$ AIHA represents a group of disorders in which the presence of autoantibodies directed against self-antigens, leads to shortened red cell survival. ${ }^{[2]}$ Anemia occurs in malaria due to invasion and destruction of red blood cells (RBCs) by malarial parasite, splenic sequestration, and ineffective erythropoiesis. Parenteral artesunate is recommended as the first-line therapy for severe and complicated malaria. ${ }^{[3]}$ While superiority in terms of survival has been proven when IV artesunate was compared to quinine in controlled trials in Asia (South East Asian Quinine Artesunate Malaria Trial [AQUAMAT] $)^{[4]}$ and Africa (AQUAMAT), ${ }^{[5]}$ little evidence is available regarding long-term side effects. There are few reports pointing out the occurrence of late onset hemolysis secondary to artesunate administration. ${ }^{[6-10]}$ However, AIHA should be considered a relatively rare cause of anemia in malaria.

We describe a very rare case of AIHA following treatment of severe malaria managed with parenteral artesunate with clinical and hemato-biochemical features indicating drug-related mechanism.

\begin{tabular}{|l|l|}
\hline \multicolumn{2}{|c|}{ Access this article online } \\
\hline Quick Response Code: & Website: \\
\hline & www.ijccm.org \\
\cline { 2 - 2 } & \\
\hline
\end{tabular}

\section{Case Report}

A 50-year-old patient presented with a history of fever associated with chills, generalized body aches and headache of 8 days duration. There was a history of yellowish discoloration of urine of 8-10 days duration. At the time of presentation, the patient was drowsy with toxic looks and features of sepsis. Clinically, he had tachycardia, tachypnea, hypotension (blood pressure-80/50), icterus, and minimal pedal edema. Systemic examination revealed mild hepatosplenomegaly with crepitation over the right infra-scapular region. Peripheral blood smear showed trophozoites of Plasmodium vivax and ring forms of plasmodium falciparum with a parasite index of $45 \%$ [Figure 1]. Arterial blood gas showed metabolic acidosis and hyperlactemia. Ultrasonography abdomen revealed hepatosplenomegaly with mild ascites. Chest X-ray posteroanterior view showed mild right-sided pleural effusion. Hemoglobin $(\mathrm{Hb})$ level was $12.5 \%$

Address for correspondence: Dr. Santosh Kumar Singh, Classified Specialist, Department of Medicine, Military Hospital, Namkum, Ranchi - 834 010, Jharkhand, India. E-mail: sksingh77@rediffmail.com

This is an open access journal, and articles are distributed under the terms of the Creative Commons Attribution-NonCommercial-ShareAlike 4.0 License, which allows others to remix, tweak, and build upon the work non-commercially, as long as appropriate credit is given and the new creations are licensed under the identical terms.

For reprints contact: reprints@medknow.com

How to cite this article: Singh S, Singh SK, Tentu AK, Kumar A, Shahbabu B, Singh V, et al. Artesunate-induced severe autoimmune hemolytic anemia in complicated malaria. Indian J Crit Care Med 2018;22:753-6. 


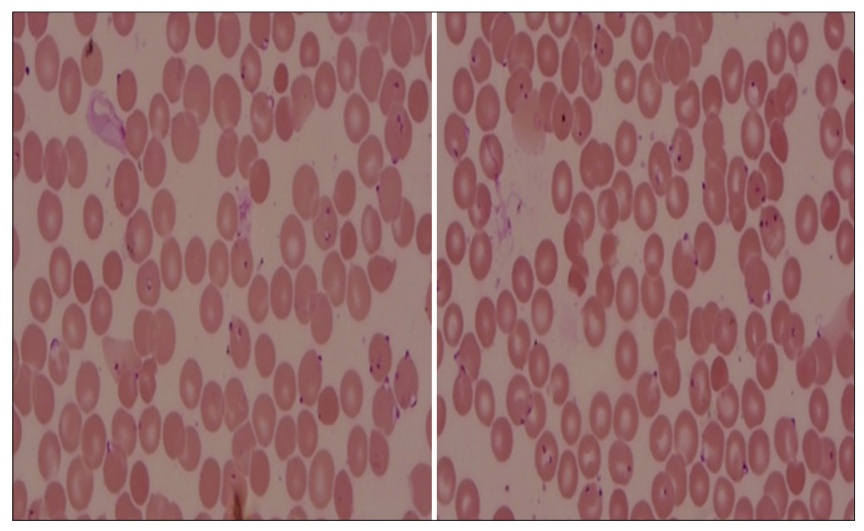

Figure 1: Peripheral blood smear showing heavy parasitemia

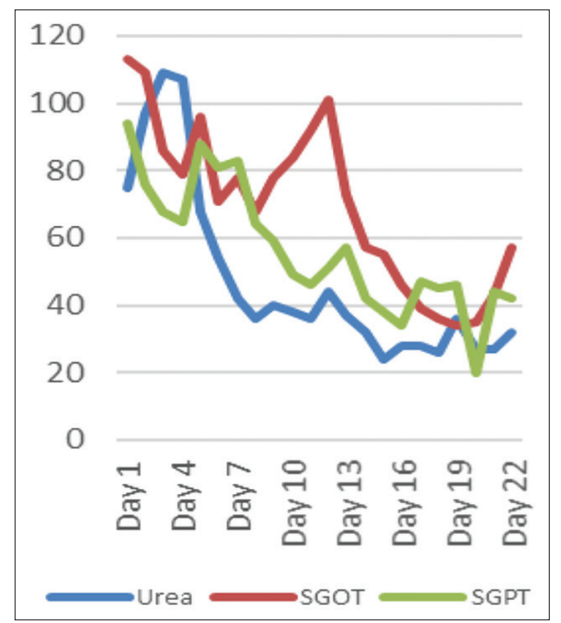

Figure 3: Renal parameter and liver function tests of the patient in days

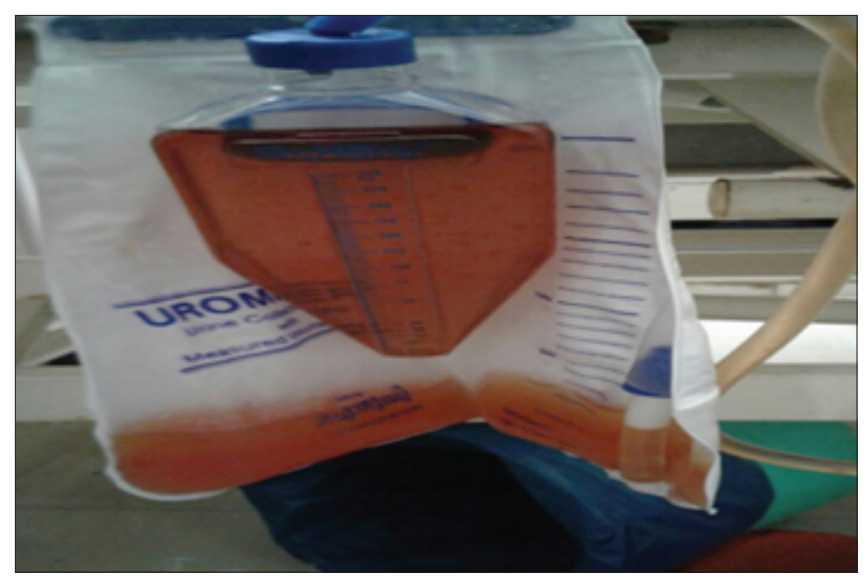

Figure 5: Cola colored urine of the patient suggestive of hemolysis

with a platelet count of 45,000 [Figure 2]. There were deranged renal parameters (serum urea-134 $\mathrm{mg}$, serum creatinine-4.6 mg) with abnormal liver function test. (Serum bilirubin-4.6 mg, aspartate aminotransferase-96 IU, alanine aminotransferase-136 IU) [Figure 3]. Based on clinical and laboratory parameters, the patient was diagnosed as a case of complicated malaria (mixed infection-BT+MT) and started on anti-malarials (injection artesunate), broad-spectrum

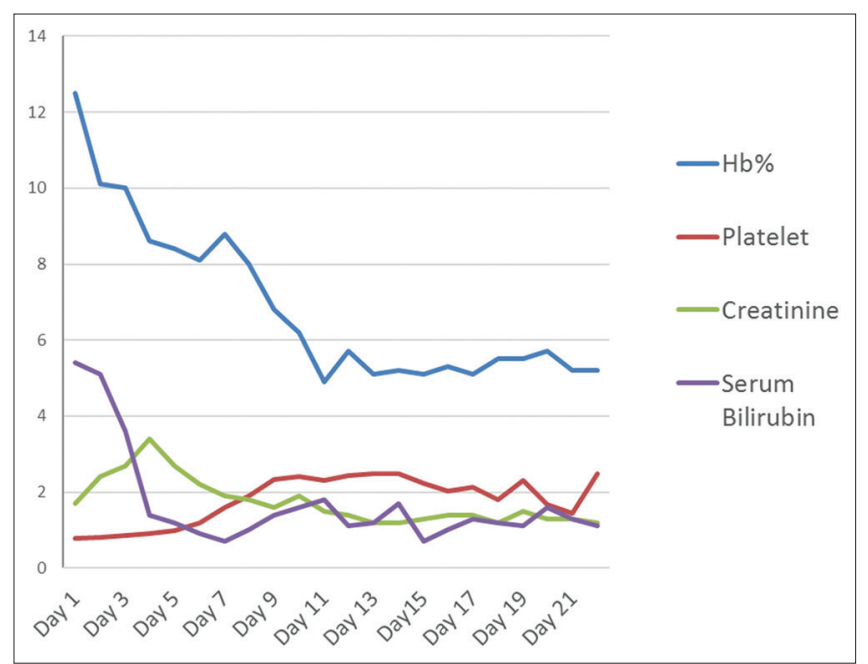

Figure 2: Hemato-biochemical parameters of the patient in days

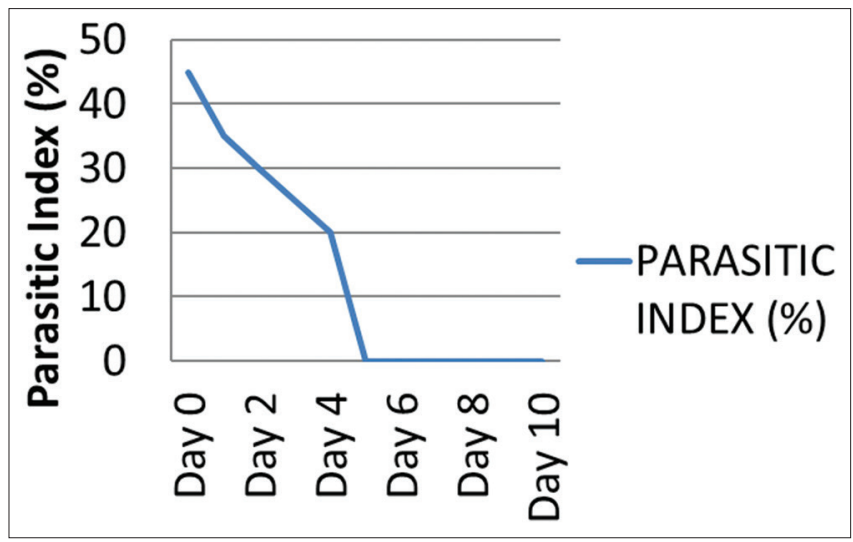

Figure 4: Parasitic index of the patient in days

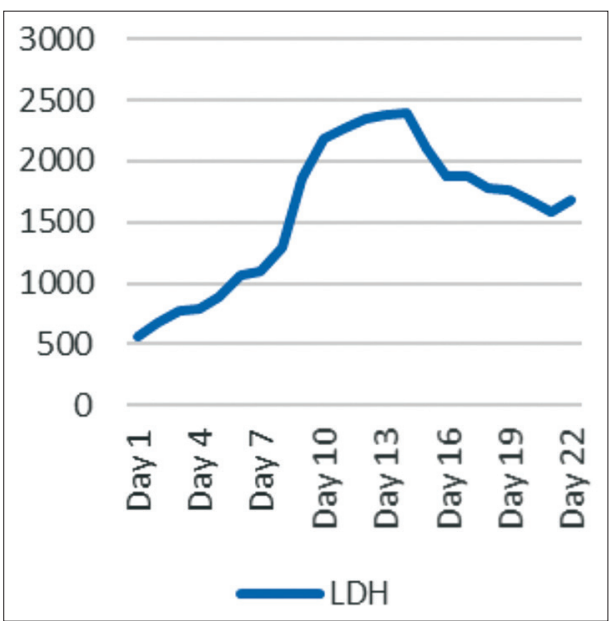

Figure 6: Levels of lactate dehydrogenase of the patient in days

antibiotics, inotropes, and supportive care. Patients condition showed steady improvement with fever settling down, and he was hemodynamically stable with lactate level returning to normal and parasitic index reduced from $45 \%$ to $<1 \%$ by the $7^{\text {th }}$ day of treatment [Figure 4]. On the $8^{\text {th }}$ day of 
treatment, the patient had cola colored urine [Figure 5] with $\mathrm{Hb}$ dropped to $8 \mathrm{~g} \%$ and lactate dehydrogenase (LDH) of 1855 [Figure 6]. Peripheral blood smear showed normocytic normochromic anaemia with features of hemolysis. Direct Coomb test was positive for immunoglobulin $\mathrm{G}(\mathrm{IgG})$ and blood sample sent for crossmatch was not compatible. On the $11^{\text {th }}$ day of admission, his $\mathrm{Hb}$ had rapidly fallen to $4.1 \mathrm{~g}$ $\%$ [Figure 2] and LDH was 2436 IU [Figure 6]. Patient had decreased haptoglobin with reticulocytosis $(3.5 \%)$ and increase in unconjugated bilirubin. Other tests to find the cause of AIHA were done. Hemoglobinopathies, enzymopathies has been ruled out. Screening for hepatotropic viruses (hepatitis $\mathrm{B}$ and $\mathrm{C}$ viruses, HIV), dengue serology, cytomegalovirus, Epstein-Barr virus, parvo B-19 viruses, and antinuclear antibody was negative. The patient was given saline washed O negative blood which showed the least incompatibility on crossmatch with uneventful post-transfusion period. His $\mathrm{Hb}$ remained lower (4.8-6.5 g\%) over the next 10 days. Given above clinical, biochemical and hematological findings, patient was diagnosed with a case of autoimmune hemolytic anemia and was started on corticosteroids (tablet methyl-prednisolone $60 \mathrm{mg}$ per day) which were progressively tapered over next 2 months. Hb level gradually increased and over 2 months follow-up became $12 \mathrm{~g} \%$. At that time, $\mathrm{LDH}$ and haptoglobin were within normal limits, and direct coombs test (DCT) was negative, both for IgG and C3d.

\section{Discussion}

Anemia is very often encountered in malaria and the most common cause is hemolysis or splenic sequestration of RBCs. ${ }^{[1]]}$ In our case, the patient had a high parasite index $(45 \%)$ at presentation with $\mathrm{Hb}$ of $11 \mathrm{~g} \%$. He was managed with I/V artesunate and other supportive measures. The $\mathrm{Hb}$ started dropping to $8.3 \mathrm{~g} \%$ by the $7^{\text {th }}$ day of treatment, and Peripheral Blood Smear (PBS) showed significant clearance of the parasites $(<1 \%)$ [Figure 4]. This fall of $\mathrm{Hb}$ can be explained by lysis of the parasitized erythrocytes; however, the $\mathrm{Hb}$ fell further to $4.5 \mathrm{~g} \%$ by the $11^{\text {th }}$ day [Figure 2]. This late fall of $\mathrm{Hb}$ was perplexing. Hemolysis was evident by reticulocyte count above 3\%, raising LDH level [Figure 6], reduced haptoglobin levels and increased unconjugated bilirubin. The test for hemoglobinopathies (Thalassemia and sickle cell disease), membranopathies (hereditary spherocytosis), and enzymopathies such as glucose-6-phosphate dehydrogenase deficiency was normal. On further evaluation, DCT was positive, which showed that anemia might be because of autoimmune reasons, likely to be artesunate induced, as other possible causes were ruled out. Raffray et al.,$^{[12]}$ in a case report reported severe delayed autoimmune hemolytic anemia following artesunate administration in severe malaria. In our case, also the autoimmune cause of hemolytic anemia is being thought and the probable reason may be artesunate injections given to the patient. The patient recovered and $\mathrm{Hb}$ level rose to $12 \mathrm{~g} \%$ over 6 weeks.

The patient was not anemic on admission and was having normal splenic size. He was started on Injectable artesunate given high parasite index. Although the peripheral blood smear showed clearing of malarial parasites, the $\mathrm{Hb}$ level started to drop, and it became $4.9 \mathrm{~g} \%$ over 11 days course. If it is a certainty that malaria was responsible for hemolytic anemia during the $1^{\text {st }}$ week, the negative finding for malarial parasites in blood smear ruled out its implication in the re-appearance of hemolysis, likely to be artesunate induced. There have been two case reports of association of malaria and autoimmune hemolysis from Korea and Canada. ${ }^{[13,14]}$ Immune-mediated hemolysis may be another mechanism responsible for artesunate related delayed hemolytic anemia. The outcome was slowly favorable while using glucocorticoids.

\section{Conclusion}

This is a rare case of AIHA following treatment of severe malaria managed with parenteral artesunate with strong co-relation for the drug immune-related mechanism. Further research is warranted to characterize the cause of post-treatment hemolysis following parenteral artesunate administration in severe malaria patients.

\section{Declaration of patient consent}

The authors certify that they have obtained all appropriate patient consent forms. In the form the patient(s) has/have given his/her/their consent for his/her/their images and other clinical information to be reported in the journal. The patients understand that their names and initials will not be published and due efforts will be made to conceal their identity, but anonymity cannot be guaranteed.

\section{Financial support and sponsorship}

Nil.

\section{Conflicts of interest}

There are no conflicts of interest.

\section{RefEREnCES}

1. Acharya S, Verma A, Singh D, Gupta V, Mahajan S. A case of Plasmodium vivax malaria associated with severe autoimmune hemolytic anaemia. Ann Trop Med Public Health 2012;5:133.

2. Böttiger L, Westerholm B. Acquired haemolytic anaemia. Acta Med Scand 2009;193:223-6.

3. Askling HH, Bruneel F, Burchard G, Castelli F, Chiodini PL, Grobusch MP, et al. Management of imported malaria in Europe. Malar J 2012;11:328.

4. Dondorp A, Nosten F, Stepniewska K, Day N, White N; South East Asian Quinine Artesunate Malaria Trial (SEAQUAMAT) group. Artesunate versus quinine for treatment of severe falciparum malaria: A randomised trial. Lancet 2005;366:717-25.

5. Dondorp AM, Fanello CI, Hendriksen IC, Gomes E, Seni A, Chhaganlal KD, et al. Artesunate versus quinine in the treatment of severe falciparum malaria in African children (AQUAMAT): An open-label, randomised trial. Lancet 2010;376:1647-57.

6. Zoller T, Junghanss T, Kapaun A, Gjorup I, Richter J, Hugo-Persson M, et al. Intravenous artesunate for severe malaria in travelers, Europe. Emerg Infect Dis 2011;17:771-7.

7. Kreeftmeijer-Vegter AR, van Genderen PJ, Visser LG, Bierman WF, Clerinx J, van Veldhuizen CK, et al. Treatment outcome of intravenous artesunate in patients with severe malaria in the Netherlands and Belgium. Malar J 2012;11:102.

8. Rolling T, Schmiedel S, Wichmann D, Wittkopf D, Burchard GD, Cramer JP, et al. Post-treatment haemolysis in severe imported 
malaria after intravenous artesunate: Case report of three patients with hyperparasitaemia. Malar J 2012;11:169.

9. Kano S. Artemisinin-based combination therapies and their introduction in Japan. J Infect Chemother 2010;16:375-82.

10. Caramello P, Balbiano R, De Blasi T, Chiriotto M, Deagostini M, Calleri G. Severe malaria, artesunate and haemolysis. J Antimicrob Chemother 2012;67:2053-4.

11. Roberts DJ, Casals-Pascual C, Weatherall DJ. The clinical and pathophysiological features of malarial anaemia. Curr Top Microbiol Immunol 2005;295:137-67.
12. Raffray L, Receveur MC, Beguet M, Lauroua P, Pistone T, Malvy D. Severe delayed autoimmune haemolytic anaemia following artesunate administration in severe malaria: A case report. Malar J 2014;13:398.

13. Lee S, Lee S, Chung B, Hwang T, Shin H. A case of Plasmodium vivax malaria associated with autoimmune hemolytic anemia. Infect Chemother 2008;40:63.

14. Drouin J, Rock G, Jolly EE. Plasmodium falciparum malaria mimicking autoimmune hemolytic anemia during pregnancy. Can Med Assoc J $1985 ; 132: 265-7$ 